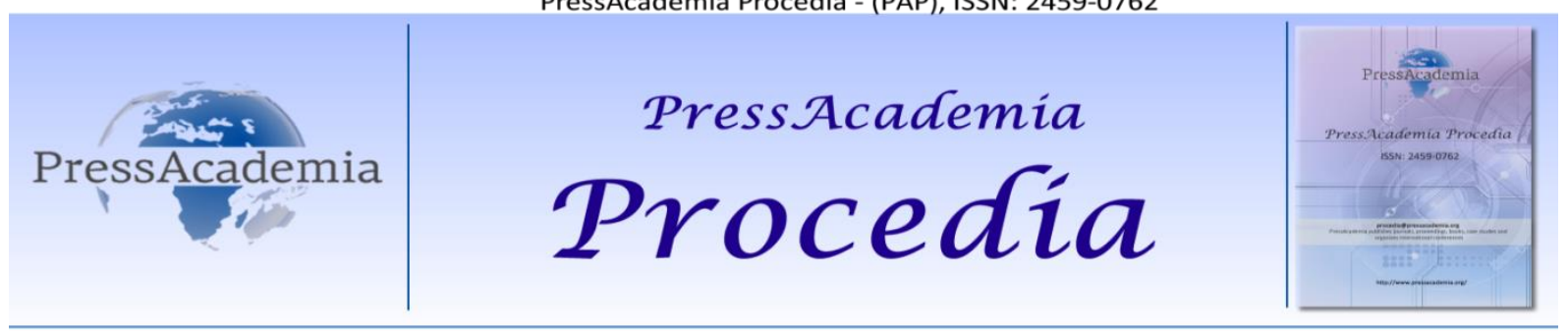

Global Business Research Congress (GBRC), May 24-25, 2017, Istanbul

\title{
EXAMINING THE LEVEL OF AWARENESS OF THE EXECUTIVE STAFF TOWARDS STRATEGIC PLANNING: A HOSPITAL EXAMPLE
}

DOI: 10.17261/Pressacademia.2017.661

PAP- GBRC-V.3-2017(87)-p.802-807

Abdullah Soysal ${ }^{1}$, Safak Kiran ${ }^{2}$

${ }^{1}$ Kahramanmaraş Sütçü İmam University, Department of Health Administration, Kahramanmaraş, Turkey, asoysall@ksu.edu.tr

${ }^{2}$ Kahramanmaraş Sütçü İmam University, Department of Health Administration, Kahramanmaraş, Turkey, skiran@ksu.edu.tr

\section{To cite this document}

Soysal A, and S. Kiran, (2017). Examining the level of awareness of the executive staff towards strategic planning: a hospital example.

PressAcademia Procedia (PAP), V.3, p.802-807.

Permemant link to this document: http://doi.org/10.17261/Pressacademia.2017.661

Copyright: Published by PressAcademia and limited licenced re-use rights only.

\begin{abstract}
The aim of this study is to examine the level of awareness of the strategic planning in terms of some variables for executive staff working at Kahramanmaraş Sütçü Imam University Health Practice and Research Hospital. In order to obtain data, questionnaires applied with face to face to 33 manager and assistant manager staff working at the hospital. The data obtained from the questionnaires were subjected to descriptive, comparative and correlational statistical analyzes using the SPSS Version 22.0 program. As a result of the analyzes, the mean of perception dimension which is sub-dimension of scale showed statistically significant differences according to the participants' status in the administrative or health units. In addition, according to the answers given by the participants, it is concluded that there is a meaningful relationship between whether there is any strategic planning activity or not in the unit and whether participants participate or not any strategic planning activity in institution. As a result, it can be argued that administrative staff have higher perceptions about strategic planning and the realization of strategic planning activities in units affects the participation to strategic planning activities on an institutional basis.
\end{abstract}

Keywords: Hospitals, Executive Staff, Strategic Planning, Strategic Management, Awareness,

JEL Codes: I12, M12, M19

\section{YÖNETICI PERSONELIN STRATEJIK PLANLAMAYA YÖNELIK FARKINDALIK DÜZEYININ INCELENMESi: BIR HASTANE ÖRNEĞi}

\section{ÖZET}

Bu çalışmanın amacı, Kahramanmaraş Sütçü İmam Üniversitesi Sağlık Uygulama ve Araştırma Hastanesinde görev yapan yönetici personelin stratejik planlamaya yönelik farkındalık düzeyini bazı değişkenler açısından analiz etmektir. Araştırma kapsamında veri elde etmek için, hastanede görev yapan 33 yönetici ve yardımcı yönetici personele yüz yüze anket uygulanmıştır. Anketlerden elde edilen veriler, SPSS Versiyon 22.0 programı kullanılarak tanımlayıcı, karşılaştırmalı ve korelasyonel istatistiki analizlere tabi tutulmuştur. Yapılan analizler sonucunda ölçek alt boyutlarından algı boyutu ortalamaları, katılımcıların idari birimlerde ya da sağlık birimlerinde görev yapma durumuna göre istatistiksel olarak anlamlı farklılık göstermiştir. Buna ek olarak katılımcıların verdikleri cevaplara göre, görev yapılan birim bazında herhangi bir stratejik planlama faaliyetinin gerçekleştirilip gerçekleştirilmemesi durumu ile kurum bazında katılımcıların herhangi bir stratejik planlama faaliyetine katılıp katılmama durumu arasında anlamlı bir ilişki olduğu sonucuna ulaşılmıştır. Sonuç olarak ortalamaların karşılaştırılması bakımından değerlendirildiğinde, idari personelin stratejik planlamaya yönelik algılarının daha yüksek olduğu ve birimlerde stratejik planlama faaliyetlerinin gerçekleştirilme durumu, yönetici ve yardımcı yönetici personelin kurum bazında stratejik planlama faaliyetlerine katılım durumunu etkilediği söylenebilmektedir.

Anahtar Kelimeler: Hastaneler, Yönetici Personel, Stratejik Planlama, Stratejik Yönetim, Farkındalık

JEL Kodları: I12, M12, M19 


\section{GiRiş}

Günümüzde, sağlık sektöründe yaşanan teknolojik ve çevresel gelişmeleri takip etmek önemli olduğu kadar bu gelişmelerin sağılık kurumlarında uygulanması da rekabet edebilmek ve ayakta kalabilmek adına büyük bir önem arz etmektedir. Bu bağlamda sağılık kurumlarına ve yöneticilerine stratejik yönetim ve planlama süreçlerini uygulamaları konusunda önemli bir sorumluluk düşmektedir. Stratejik yönetim ve stratejik planlamanın önemli işlevleri arasında işletmenin stratejik yönlerini ortaya koymak, kaynakların verimli kullanılmasına öncülük etmek ve mükemmellik standartlarını belirlemek olarak sıralanabilir. Bu kapsamda değerlendirildiğinde, sağılı yöneticilerinin kurumun stratejik hedefleriyle ilgili standartları belirleyebilen ve bunu yaparken de ülkedeki stratejik sağlık planlamasında yer alan hedeflerle uyumlu hale getirebilen kişiler olması büyük bir öneme sahiptir (Soylu ve İleri, 2010, s.79). Stratejik planlama, tüm organizasyon türleri için ve özellikle de sağıı kurumları için kullanışlı ve geçerli bir araç olarak değerlendirilebilir. Sağlık kurumlarında hangi planlama aracının uygun ve geçerli olduğu hizmetlerin çeşitliliği, birimlerin büyüklüğü ve karmaşıklık düzeyine göre değişmektedir. Herhangi bir serviste (örn: kardiyoloji, dahiliye) yapılacak olan planlamanın uygun olup olmadığı, daha üst seviyede diğer servis/birimlerde yapılan planlamayla aynı amaç ve doğrultuda yapıımasına bağlıdır (Pereira, F.P.R, Peiro, M., 2012, s.749). Hizmetlerin birbiriyle yakın ilişki içerisinde olması sağlık kurumlarında planlama faaliyetlerinin koordineli bir şekilde gerçekleştirilmesini gerektirmektedir. Her birim sorumlusunun planlama sürecindeki sorumluluğu kendisine düşen rolün temel ve gerekli bir parçasıdır.

Stratejik planlama süreci sağlık kurumlarında uygulanabilir yöntemler sunmaktadır. Bu yöntemler, planlama süreci içerisinde sağılı kurumlarının geleceğe dönük uygun ve kalıcı bir dönüşüme odaklanabilmesi için kısa, orta ve uzun vadede programlanabilir, sistematik, rasyonel, bütün ve birleşik bir özellik göstermektedir (Pereira, F.P.R, Peiro, M., 2012, s.749). Sağlık kuruluşlarında iyi bir stratejik planlama için SWOT (GZFT) analizi, denge analizi (Equririum Analysis) ve performans güçleri analizi gibi stratejik planlama araçları kullanılabilmektedir (Sonğur vd., 2013: 75). Bunlar arasında özellikle SWOT (GZFT) analizi bir organizasyonun mevcut durumunun ortaya konulması ve güçlü yönlerinin ortaya koyulması açısından önemli bir planlama aracı olup, yöneticilerin stratejik planlama farkındalık düzeyinin belirlenmesi bu analiz içerisinde değerlendirilebilir. Bu kapsamda çalışmanın amacı hastanelerde yönetim sorumluluğu olan personelin stratejik planlamaya yönelik farkındalık düzeyinin bazı mesleki ve sosyo-demografik özellikler bakımından incelenmektir. Literatürde ilk olarak strateji, stratejik yönetim ve stratejik planlama konusunda kavramsal bir çerçeve sunularak să̆lık hizmetlerinde planlamanın gerekliliğine ve planlamayı zorlaştıran nedenlere kısaca değinilecektir.

\section{LITERATÜR INCELEMESI}

Strateji, uzun vadede varılmak istenen hedefe yönelik izlenen yol olarak tanımlanmaktadır. Mintzberg'e (1989) göre işletme yönetiminde strateji kavramı; "bir işletmenin içinde yer aldığı ortamın dinamizmine karşın, kararlılığını koruyarak varlığını sürdürmek ve pazarda başarı elde etmek için seçtiği yolu betimlemektedir" (Wikipedia,2016). Ayrıca, Mintzberg stratejiyi tek yönlü olarak ele almamış plan, şaşırtma, örüntü, konumlama ve perspektif olarak beş farklı kavramla ilişkilendirmiştir. Plan olarak stratejiyi; "sorunların üstesinden gelmek için izlenen bir dizi bilinçli, niyetli hareket tarzı ve rehber niteliğinde ilkeler" olarak tanımlamıştır. Buna göre, bir çocuğun kendisine koyulan engelleri aşmak için ve bir şirketin mevcut pazarda rakiplerine üstünlük sağlamak için bir stratejisi vardır. Bu çerçevede stratejilerin iki özelliğinden bahsedilmiştir. Birincisi, stratejiler uygulanmak üzere önceden planlanan faaliyetlerdir ve ikincisi stratejiler bilinçli ve amaçlı olarak geliştirilirler (Mintzberg, 1987:11). Stratejik yönetim ise, belirlenen amaçlar doğrultusunda organizasyonun nereye gittiği ve nereye gitmesi gerektiği ile ilgili bir kavramdır. Drucker stratejik yönetimi, "belirlenen amaçlar doğrultusunda alınan kararların gelecekteki sonuçları vermesini sağlamak" olarak tanımlamıştır (Güçlü, 2003:70). Stratejik yönetim, uzun vadede işletmelerin ihtiyaçlarını belirlemesi ve bu ihtiyaçların giderilmesi için kaynakların temin edilmesi ve idaresi anlamına da gelmektedir. Yöneticiye örgütün içsel ve dışsal çevresinde yaşanan gelişmeleri analiz edebilmesine yönelik seçenekler sunması stratejik yönetimin önemli bir özelliği olarak değerlendirilmektedir (Üstüner, 2013, s.62). Sağlık hizmetleri açısından uzun vadede amaçların belirlenmesi ve bu amaçlara ulaşabilmek için gerekli kaynakların temin edilmesi ve özellikle hızla gelişen ve değişen teknolojiyle karşı karşıya olması bakımından stratejik yönetim büyük bir öneme sahiptir (Soylu ve ileri, 2010, s.80). Stratejik planlama, örgütün bu günkü durumundan gelecekte arzuladığı duruma ulaşmak için süreçlerin planlandığı ve belirli göstergelerin oluşturulduğu sistematik ve organize bir süreç olarak tanımlanmaktadır (Tüzün, 2008, s.7). Stratejik planlamadaki strateji kelimesinin işletme yönetimi alanındaki karşılı̆̆ genelde uzun vadede varılmak istenen amaca yönelik izlenen yol olarak değerlendirildiği bilinmektedir. Ancak işletme yapılarına göre uzun vadenin sınırları farklılık göstermektedir. Bazı araştırmacılara göre uzun vadenin sınırı tahmin yapılabilecek süreyle sınırlıdır (Ülgen ve Mirze, 2010:29). Bu bakımdan sağlık hizmetlerindeki risk ve belirsizliklerin yoğunluğu göz önüne alındığında bu sınırın bir yıldan daha az süreçleri kapsadığını söylemek mümkündür. Sağlık sektörü, maliyetleri azaltmak ve istisnai bir hizmet sunmak için büyük bir baskı altındadır. Sağlık yöneticileri ise bu baskı altında kaliteli sağılı hizmet sunumunu tesis etmek ve sürdürmek, buna ek olarak maliyetleri minimum düzeyde tutarak verimliliği sağlamak için stratejik planlamayı bir araç olarak kullanmak durumundadır (Butler vd. 1996:137). Bu bağlamda sağlık hizmetlerinde stratejik planlamayı gerektiren daha farklı durumlardan söz etmek mümkündür. Bu kapsamda Pereira ve Peiro (2012) yaptıkları çalışmada hastanelerde stratejik planlama uygulamalarının neden gerekli olduğunu beş farklı açıdan değerlendirmiştir (Pereira, F.P.R, Peiro, M., 2012, s.749). Buna göre; 
- Hastaların artan bilgi düzeyi, haklarının farkında olmaları, daha çok talepte bulunmaları, alternatif hizmet sunucularının sayısındaki artış ve verdikleri kararların finansal bir sonucunun olması.

- $\quad$ Yetenekli ve profesyonel rakipler, büyük şehirlerdeki kaliteli eğitim görmüş sağılık profesyonelleri ve bunlara ulaşımın yaygınlığı ve kolaylığı.

- Hizmet üretimi için kaynakların kıtlığı.

- $\quad$ Sadece hizmetin kalitesi değil, hizmeti sunum biçiminin de hastaların tercihinde büyük bir önem kazanması.

- $\quad$ Artan popülasyon ve buna bağlı olarak farklı hizmet ihtiyaçlarının ortaya çıkması, bunun yanında tanı ve tedavi yöntemlerindeki seçeneklerin artmasıyla farklılaşan, büyüyen ve daha karmaşık yapılar hale gelen hastaneler sağlık kurumlarında stratejik planlamayı gerekli hale getirmektedir.

Sağlık hizmetlerinde planlama son yıllarda karar vericilerin dikkatini önemli ölçüde çeken konular arasında yer almaktadır. Bu durumun altında yatan nedenlerin başında artan maliyetler ve sürekli artan hizmet talebi bulunmaktadır. Buna karşın sağlık hizmetlerinde planlama faaliyetleri üretim işletmelerine kıyasla geride kalmıştır. Hans vd. (2012) yaptıkları çalışmada bu durumun dört temel sebebinden bahsetmiştir (Hans vd., 2012:304). Buna göre;

- Sağlık hizmetlerinde bazı gruplar (hekimler, yöneticiler vb.) arasında sıkça yaşanan çatışmalar ve gruplar arasında iş birliği ve bağlılık konusunda eksikliklerin olması.

- Mevcut bilgi sistemlerinin planlama için hayati öneme sahip bilgileri sağlama konusunda yetersiz olması, ayrıca, Tanıya İlişkin Gruplar ve elektronik hasta kayıt sistemlerinin finansal ve klinik bilgi yönetim sistemlerine olan intiyacı ortaya koymasına rağmen bu sistemlerin faaliyet bilgi sistemleriyle entegrasyon konusunda eksik kalması organizasyon genelinde planlamayı zorlaştırmaktadır.

- $\quad$ Genellikle hastanelerde özerk olarak yönetilen birimlerin bulunması ve bu birimlerdeki yöneticilerin kendi birimlerinden başka birimlerle iş birliği eğiliminde olmaması planlama işlevini bağımsız parçalara ayırmakta ve zorlaştırmaktadır.

- $\quad$ Planlamanın tüm hasta nüfusunu ilgilendirmesine karşın hekimlerin yalnızca tedavi ettikleri hastalara odaklanması.

\section{VERI VE YÖNTEM}

Bu çalışmada, yönetim sorumluluğu bulunan hastane personelinin stratejik planlamaya yönelik farkındalık düzeylerinin bazı değişkenler açısından incelenmesi amaçlanmıştır. Çalışma evrenini Kahramanmaraş Sütçü İmam Üniversitesi Sağlık Uygulama ve Araştırma Hastanesinde görev yapan ve yönetim sorumluluğu bulunan personel oluşturmaktadır. Veri elde etmek amacıyla 33 kişiye yüz yüze anket uygulanabilmiştir. Anketin ilk kısmında, Yakut ve Korkmazyürek (2012) tarafından stratejik planlama farkındalığını belirlemek üzere geliştirilen stratejik planlama farkındalığı ölçeği yer almaktadır (Yakut ve Korkmazyürek, 2012). Ölçek, "Bilgi=11 ifade", "Algı=10 ifade" ve "Süreç=8 ifade" olmak üzere üç boyut ve toplamda, 5'li likert sistemine göre derecelendirilmiş 29 ifadeden oluşmaktadır. Anketin ikinci kısmı, katılımcılara ilişkin sosyo-demografik özelliklerin yanında spesifik amaçlı sorularında yer aldığı toplam 11 sorudan oluşmaktadır. Elde edilen veriler IBM SPSS (Statistical Package for The Social Sciences) Version 22 programından yararlanılarak tanımlayıcı, korelasyonel ve karşılaştırmalı istatistik yöntemleri kullanılarak analiz edilmiştir.

\section{BULGULAR VE TARTIŞMA}

Tablo 1'e göre; katılımcıların \%57,6'sı kadınlardan ve \%42,4'ü erkeklerden oluşmaktadır. Yaş durumuna bakıldığında \%36,4 oranında hem 28-33 yaş aralığındaki hem de 34-39 yaş aralığındaki katılımcı oranının eşit olduğu, 40 yaş ve üzeri katılımcı oranının \%15,1 ve 22-27 yaş aralığındaki katılımcı oranının \%12,1 olduğu görülmektedir. Eğitim düzeyine göre \%33,3 oranında lisans ve $\% 36,3$ oranında lisansüstü eğitim düzeyine sahip katılımcıların ağılıkta olduğu ve bunu \%27,3 oranıyla önlisans ve \%3,1 oranıyla ortaöğretim eğitim düzeyine sahip katılımcıların takip ettiği görülmektedir. Deneyim durumuna göre 7-10 yıl arası deneyime sahip katılımcıların \%42,4 ile en yüksek katılım oranına sahip olduğu ve bunu \%33,3 ile 11 yıldan fazla deneyime sahip katılımcıların takip ettiği ve 6 yıldan az deneyime sahip katılımcıların \%24,3 ile en az katılım oranına sahip olduğu görülmektedir. Katılımcıların $\% 54,5^{\prime}$ i idari birimlerde görev yapmakta ve $\% 45,5^{\prime} i$ ise sağlık birimlerinde görev yapmaktadır. Nitelik bakımından katılımcıların $\% 57,6$ 'sı yöneticilerden ve $\% 42,4$ 'ü ise yönetici yardımcılarından oluşmaktadır. Gelir durumuna göre katılımcıların \%63,6'lık kısmının 2501-3500 TL arasında gelire sahip olduğu, \%24,3'ünün 1500-2500 TL arasında gelire sahip olduğu ve \%12,1'inin 3501 TL ve üzerinde gelire sahip olduğu görülmektedir.

Tablo 1: Katılımcıların Sosyo-Demografik Özelliklerine İlişkin Bulgular

\begin{tabular}{|c|c|c|c|c|c|}
\hline 1.Yaş & $\mathbf{N}$ & $\%$ & 2. Cinsiyet & $\mathbf{N}$ & $\%$ \\
\hline $22-27$ yaş & 4 & 12,1 & Erkek & 14 & 42,4 \\
\hline 28-33 yaş & 12 & 36,4 & Bayan & 19 & 57,6 \\
\hline 34-39 yaş & 12 & 36,4 & TOPLAM & 33 & 100 \\
\hline 40 yaş ve üzeri & 5 & 15,1 & 4.Gelir & $\mathbf{N}$ & $\%$ \\
\hline TOPLAM & 33 & 100 & $1500-2500 \mathrm{TL}$ & 8 & 24,3 \\
\hline 3.Eğitim & $\mathbf{N}$ & $\%$ & 2501-3500 TL & 21 & 63,6 \\
\hline Ortaöğretim & 1 & 3,1 & 3501 TL ve üzeri & 4 & 12,1 \\
\hline
\end{tabular}




\begin{tabular}{lll|lll}
\hline Önlisans & 9 & $\mathbf{2 7 , 3}$ & TOPLAM & 233 & 100 \\
\hline Lisans & 11 & 33,3 & 6.Departman & $\mathbf{N}$ & $\mathbf{\%}$ \\
\hline Lisansüstü & 12 & 36,3 & İdari & 18 & 54,5 \\
\hline TOPLAM & 33 & 100 & Sağlık & 15 & 45,5 \\
\hline 5.Deneyim & $\mathbf{N}$ & $\mathbf{\%}$ & TOPLAM & 33 & 100 \\
\hline$\leq 6$ yıl & 8 & 24,3 & $\mathbf{7 . N i t e l i k}$ & $\mathbf{N}$ & $\mathbf{\%}$ \\
\hline $7-10$ yıl & 14 & 42,4 & Yönetici & 19 & 57,6 \\
\hline$\geq 11$ yıl & 11 & 33,3 & Yönetici yardımcıSı & 14 & 42,4 \\
\hline TOPLAM & 33 & 100 & TOPLAM & 33 & 100 \\
\hline
\end{tabular}

Tablo 2'de ölçeğe yönelik geçerlik çalışmasına ilişkin bulgulara yer verilmiştir. Ölçeğin geçerlik analizi daha önce doğrulayıcı faktör analizi kullanılarak gerçekleştirildiğinden bu çalışmada ölçeğin güvenirlik analizi yapılmıştır.

Tablo 2: Ölçeğinin Geçerliğine ilişkin Bulgular

Geçerliğe İlişkin, Doğrulayıcı Faktör Analizinde ilişkilendirme Sonrası Uyum Değerleri

\begin{tabular}{c|llllllllll}
\hline $\begin{array}{c}\text { Farkındalık } \\
\text { Ölçeği }\end{array}$ & $\Delta X^{2}$ & sd & $\Delta X^{2} / s d$ & RMSEA & RMR & GFI & IFI & TLI & CFI & ECVI \\
\hline Íkincil Seviye & 1149,8 & 371 & 3,099 & 0,089 & 0,084 & 0,758 & 0,788 & 0,766 & 0,786 & 4,822 \\
\hline
\end{tabular}

Kaynak: Yakut, H. ve Korkmazyürek, H. (2012). Stratejik Planlama Farkındalığı İçin Bir Ölçek Geliştirme Çalışması: Güvenirliği ve Geçerliği. Çağ Üniversitesi Sosyal Bilimler Dergisi, vol.9, no.2, p.159-170.

Ölçeğin güvenirliği alfa değeri baz alınarak hesaplanmıştır. Yapılan çalışmalarda alfa değerinin 0,7'nin üzerinde kabul edilebilir olduğunu öngören araştırmacılara rastlamak mümkündür (Bland \& Altman, 1997, Tavakol \& Dennick, 2011:54). Bu çalışmada da kabul edilebilir bir alfa değerinin en az ,70 olması arzu edilmektedir. Tablo 3'de çalışmada kullanılan ölçeğin ve ölçeğe bağlı 3 alt boyutun iç tutarlıık katsayıları gösterilmiştir. Bu katsayı stratejik planlama farkındalığı ölçeği için 0,869, bilgi boyutu için 0,827 , algı boyutu için 0,932 ve süreç boyutu için 0,786 olarak hesaplanmıştır. Genel olarak bu değerlerin kabul edilebilir değerin üzerinde olduğu ve ölçeğin güvenilir olduğu görülmektedir.

Tablo 3: Ölçeğin Güvenirliğine illişkin Bulgular

Güvenirliğe ilişskin Cronbach Alpha Değerleri

\begin{tabular}{lll}
\hline Ölçek & Ifade Sayısı & Cronbach Alpha \\
\hline Stratejik Planlama Farkındalığı Ölçeği & $\mathbf{2 9}$ &, 869 \\
\hline Bilgi Boyutu & 11 &, 827 \\
\hline Algı Boyutu & 10 &, 932 \\
\hline Süreç Boyutu & 8 &, 786 \\
\hline
\end{tabular}

Tablo 4, yönetim sorumluluğu bulunan personelin idari birimlerde ya da sağlık birimlerinde çalışma durumuna göre stratejik planlamaya yönelik algılarının farklılaşıp farklılaşmadığını ortaya koymaktadır. Buna göre ölçek alt boyutlarından algı boyutu çalışılan birime göre $(p=, 044<p=, 05)$ anlamlı olarak farklılık göstermiştir. Ortalamaların karşılaştırılması bakımından değerlendirildiğinde stratejik planlamaya yönelik algının idari personellerde daha yüksek olduğu sonucuna ulaşılmıştır.

Tablo 4: Algı Boyutunun Görev Yapılan Birime Göre Anlamlı Olarak Farklılaşıp Farklılaşmadı̆̆ına ilişskin T Testi Sonuçları

\begin{tabular}{lllllll}
\hline Ölçek & Departman & N & Mean & S.D & F & P \\
\hline \multirow{2}{*}{ Algı Boyutu } & İdari & 18 & 4,2889 &, 61919 & \\
\cline { 2 - 5 } & Sağlık & 15 & 3,9000 &, 644 &, 044
\end{tabular}

Tablo 5'te birim bazında herhangi bir stratejik planlama faaliyetinin gerçekleştirilip gerçekleştirilmeme durumu ile kurum bazında herhangi bir stratejik planlama faaliyetine katılıp katılmama durumu arasında anlamlı bir ilişkinin olup olmadığı ortaya koyulmuştur. Buna göre iki durum arasında $(p=, 000<p=, 05)$ anlamlı bir ilişki olduğu sonucuna ulaşılmıştır. Tablo incelendiğinde birim bazında SP faaliyetlerinin gerçekleştirildiğini belirten personelin oranının $\% 54,6$ ile çoğunlukta olduğu ve bu personelin \%88,9'unun kurum bazında SP faaliyetlerine katıldığı görülmektedir. Ayrıca birimlerde SP faaliyetlerinin gerçekleştirilmediğini ifade eden personelin oranının $\% 45,4$ olduğu ve bu personelin de $\% 73,3$ oranında kurum bazında SP faaliyetlerine katılmadığı görülmektedir. 
Tablo 5: Birim Bazında "SP" Faaliyetinin Gerçekleştirilme Durumu ile Kurum Bazında "SP" Faaliyetine Katılma Durumu Arasında İlişki Olup Olmadığına Yönelik Ki-Kare (Chi-Square) Testi Sonuçları

\begin{tabular}{|c|c|c|c|c|c|c|}
\hline & & $\begin{array}{l}\text { Kurum } \\
\text { faaliye } \\
\text { durum }\end{array}$ & e katılma & & $\begin{array}{l}\text { Pearson Chi-Square } \\
\text { Value }\end{array}$ & $\begin{array}{l}\text { Asymp. Sig. (2- } \\
\text { sided) }\end{array}$ \\
\hline \multirow{9}{*}{$\begin{array}{l}\text { Birimde SP } \\
\text { faaliyetlerinin } \\
\text { gerçekleştirilme } \\
\text { durumu }\end{array}$} & & Evet & Hayır & Toplam & \multirow{9}{*}{13,268} & \multirow{9}{*}{,000 } \\
\hline & Evet & 16 & 2 & 18 & & \\
\hline & & $88,9 \%$ & $11,1 \%$ & $100 \%$ & & \\
\hline & & $48,5 \%$ & $6,1 \%$ & $54,6 \%$ & & \\
\hline & Hayır & 4 & 11 & 15 & & \\
\hline & & 26,7 & $73,3 \%$ & $100 \%$ & & \\
\hline & & $12,1 \%$ & $33,3 \%$ & $45,4 \%$ & & \\
\hline & Toplam & 20 & 13 & 33 & & \\
\hline & & $60,6 \%$ & $39,4 \%$ & $100 \%$ & & \\
\hline
\end{tabular}

Tablo 6'da Tablo 5'te ifade edilen ilişkinin yönü ve büyüklüğüne ilişkin durumu saptamak üzere korelasyon analizi sonucuna yer verilmiştir. Bu sonuca göre birim bazında stratejik planlama faaliyetinin gerçekleştirilme durumu ile kurum bazında herhangi bir stratejik planlama faaliyetine katılma durumu arasında $(p=, 000<p=, 01)$ anlamlı bir ilişki olduğu sonucuna ulaşılmıştır. İlişkinin yönü $( \pm)$ ve düzeyine $(r)$ ilişkin değerlere bakıldığında elde edilen korelasyon katsayısına $(r=, 634)$ göre pozitif yönlü orta düzeyde ilişki olduğu sonucuna varılmıştır. Kalaycı (2014) yaptığı çalışmada, korelasyon katsayısının ,50-,69 arasındaki değerlerine göre orta düzeyde bir ilişkinin var olduğunu belirtmiştir (Kalaycı, 2014:116).

Tablo 6: Birim Bazında "SP" Faaliyetinin Gerçekleştirilme Durumu ile Kurum Bazında "SP" Faaliyetine Katılma Durumu Arasında iliş̧kinin Yönü ve Düzeyine İlişkin Korelasyon Analizi Sonuçları

\begin{tabular}{|c|c|c|c|c|}
\hline & Mean & S.D & 1 & 2 \\
\hline $\begin{array}{l}\text { Birimde SP } \\
\text { faaliyetlerinin } \\
\text { gerçekleştirilme } \\
\text { durumu (1) }\end{array}$ & 1,4545 & ,505 & 1 & \\
\hline $\begin{array}{l}\text { Kurumda SP } \\
\text { faaliyetlerinin ye } \\
\text { katılma durumu (2) }\end{array}$ & 1,3939 & 496 &, $634 * *$ & 1 \\
\hline
\end{tabular}

\section{SONUÇ}

Araştırma bulguları incelendiğinde stratejik planlamaya yönelik algının çalışılan birimin idari birim ya da sağlık birimi olmasına göre anlamlı olarak farklılaştığı sonucuna ulaşılmıştır. Ortalamaların karşılaştırııması bakımından değerlendirildiğinde idari birimlerde görev yapan personelin SP faaliyetlerine yönelik algılarının daha yüksek olduğu söylenebilmektedir. Bu durumun sebebi olarak SP faaliyetlerinin daha çok idari amaçlı faaliyetlermiş gibi düşünülmesinden kaynaklandığı düşünülmektedir. Stratejik planlamanın başarıya ulaşabilmesi ortak değer ve ilkelerin örgüt üyeleri tarafından benimsenmesine bağlıdır (Küçüksüleymanoğlu, 2008:405). Sağlık kurumlarında ortak değer ve ilkelerin benimsenmesi idari personelin ve sağlık personelinin iş birliği anlamına gelebilmektedir. Bu iş birliğinin stratejik planlama faaliyetlerine yönelik ortak algıyı geliştirebileceği düşünülmektedir. Araştırmada birim bazında SP faaliyetlerin gerçekleştirilip gerçekleştirilmeme durumu ile kurum bazında SP faaliyetlerine katılıp katılmama durumu arasında bir ilişkinin bulunduğu sonucuna ulaşılmıştır. Bu ilişkinin pozitif yönlü orta düzey bir ilişki olduğu saptanmıştır. Buna göre birim bazında gerçekleştirilen SP faaliyetlerinin kurum bazındaki SP faaliyetlerine katılımı etkilediği düşünülmektedir. Bu bağlamda kurumun belirli bir vadede belirlediği hedeflere ulaşabilmesinin daha alt düzeyde gerçekleştirilen SP faaliyetlerine bağı olabileceği söylenebilmektedir. Sağlık sektöründe teknoloji ve tıp alanında yaşanan hızlı gelişmeler beraberinde rekabeti ve talep yoğunluğunu da getirmiştir. Bu bağlamda hem talebin yönlendirilebilmesi hem de bu talebin karşılanabilmesi aynı zamanda rekabet edebilme gücünün kaybedilmemesi için kaynakların etkin bir biçimde yönetilmesi gerekmekte bu da planlama faaliyetlerinin daha uzun vadelere yayılmasına bağlı olmaktadır. Sağlık hizmetlerinde uzun vade, hizmetin niteliği düşünüldüğünde diğer sektörlere nazaran daha kısadır. Aynı zamanda hizmete olan talebin süresinin ve miktarının belirlenememesi durumu daha kritik bir seviyeye taşımaktadır. Dolayısıyla hem sağlık personeli hem de idari personelin birim bazında ve kurum bazında gerçekleştirilen planlama faaliyetlerine katılması ve iş birliğinin sağlanması büyük önem arz etmektedir. Sonuç olarak sağlık hizmetlerinde etkin bir planlamanın gerçekleştirilmesi için yöneticilere büyük sorumluluklar düşmektedir. Yönetici ve yönetici yardımcılarının stratejik planlama konusundaki farkındalık düzeyinin yüksek olması beraberinde planlama başarısını da getirecektir. Bu bağlamda, farkındalık düzeyinin yükseltilmesi için daha üst düzeydeki karar vericilerin bu konuda yönlendirmesi ve desteklemesi gerekmektedir. Ayrıca akademisyenlerin bu alanda yol gösterebilecek uygulama çalışmalarına ağırlık vermeleri önerilmektedir. 


\section{KAYNAKLAR}

Bland, J. M., Altman, D. G. (1997). Statistics Notes: Cronbach's Alpha. Bmj, 314(7080), 572. doi: https://doi.org/10.1136/bmj.314.7080.572

Butler, T.W., Leong, G.K., Everett, L.N. (1996). The Operations Management Role in Hospital Strategic Planning. Journal of Operations Management, vol.14, p.137-156. https://doi.org/10.1016/0272-6963(95)00041-0

Güçlü, N. (2003). Stratejik Yönetim. Gazi Eğitim Fakültesi Dergisi, vol.23, no.2, 61-85. http://doi.org/10.17152/gefd.80435

Hans, E. W., Van Houdenhoven, M., Hulshof, P. J. (2012). A Framework For Healthcare Planning And Control. In Handbook of Healthcare System Scheduling, p. 303-320. Springer US.

Kalaycı, Ş. (2014). SPSS Uygulamalı Çok Değişkenli İstatistik Teknikleri (6. Baskı), Asil Yayın Dağıtım, Ankara.

Küçüksüleymanoğlu, R. (2008). Stratejik Planlama Süreci. Kastamonu Eğitim Dergisi, vol.16, no.2, p.403-412.

Mintzberg, H. (1987). The Strategy Concept I: Five Ps For Strategy. California Management Review, vol.30, no.1, p.11-24. http://doi.org/10.2307/41165263

Pereira, F. P. R., Peiró, M. (2012). Strategic planning in healthcare organizations. Revista Española de Cardiología (English Edition), vol.65, no.8, p. 749-754.http://dx.doi.org/10.1016/j.rec.2012.04.004

Sonğur, C., Top, M., Tekingündüz, S. (2013). Sağlık Sektöründe GZFT (Güçlü-Zayıf Yönler-Fırsatlar-Tehditler) Analizi. Sağlıkta Performans Ve Kalite Dergisi, vol.5, p.69-100.

Soylu, Y., İleri, H. (2010). Hastanelerde Stratejik Yönetim Uygulamaları: S.Ü. Meram Tıp Fakültesi Örneği. Selçuk üniversitesi Sosyal Bilimler Meslek Yüksek Okulu Dergisi, vol.13, no.1, p. 79-96.

Tavakol, M., Dennick, R. (2011). Making Sense of Cronbach's Alpha. International Journal of Medical Education, vol.2, p.53-55. https://doi.org/10.5116/ijme.4dfb.8dfd

Tüzün, G. (2008). Sivil Toplum Kuruluşları İçin Rehberler: Kurumsal Stratejik Planlama, Tuna Matbaacılık San ve Tic. Aş., ANKARA.

Ülgen, H., Mirze, S.K. (2010). İşletmelerde Stratejik Yönetim (5. Baskı), Beta Basım Yayın A.Ş., İstanbul.

Üstüner, M. (2013). Örgütsel Tükenmişlik ile Stratejik Yönetim Arasındaki Etkileşim Üzerine Bir Uygulama. KSÜ Sosyal Bilimler Dergisi, vol.10, no.2, p.57-74.

Wikipedia, (2016). 7 Nisan 2017 tarihinde https://tr.wikipedia.org/wiki/Strateji. adresinden ulaşılmıştır.

Yakut, H. ve Korkmazyürek, H. (2012). Stratejik Planlama Farkındalığı İçin Bir Ölçek Geliştirme Çalışması: Güvenirliği ve Geçerliği. Çağ Üniversitesi Sosyal Bilimler Dergisi, vol.9, no.2, p.159-170. 